\title{
A systematic study of the effect of the hard end-group composition on the microphase separation, thermal and mechanical properties of supramolecular polyurethanes
}

Article

Accepted Version

Creative Commons: Attribution-Noncommercial-No Derivative Works 4.0

Hermida Merino, D., Feula, A., Melia, K., Slark, A. T., Giannakopoulos, I., Siviour, C. R., Buckley, C. P., Greenland, B., Liu, D., Gan, Y., Harris, P., Chippindale, A., Hamley, I. and Hayes, W. (2016) A systematic study of the effect of the hard end-group composition on the microphase separation, thermal and mechanical properties of supramolecular polyurethanes. Polymer, 107. pp. 368-378. ISSN 0032-3861 doi: https://doi.org/10.1016/j.polymer.2016.07.029 Available at https://centaur.reading.ac.uk/69191/

It is advisable to refer to the publisher's version if you intend to cite from the work. See Guidance on citing.

To link to this article DOI: http://dx.doi.org/10.1016/j.polymer.2016.07.029

Publisher: Elsevier

All outputs in CentAUR are protected by Intellectual Property Rights law, 
including copyright law. Copyright and IPR is retained by the creators or other copyright holders. Terms and conditions for use of this material are defined in the End User Agreement.

\section{www.reading.ac.uk/centaur}

\section{CentAUR}

Central Archive at the University of Reading

Reading's research outputs online 


\title{
A systematic study of the effect of the hard end-group composition on the microphase separation, thermal and mechanical properties of supramolecular polyurethanes
}

Daniel Hermida Merino, ${ }^{a}$ Antonio Feula, ${ }^{a}$ Kelly Melia, ${ }^{a}$ Andrew T. Slark,${ }^{b}$ Ioannis Giannakopoulos, ${ }^{c}$ Clive R. Siviour ${ }^{c}$ C. Paul Buckley, ${ }^{c}$ Barnaby W. Greenland, ${ }^{d}$ Dan Liu, ${ }^{e}$ Yu Gan, ${ }^{a}$ Peter J. Harris, ${ }^{a}$ Ann M. Chippindale, ${ }^{a}$ Ian W. Hamley ${ }^{a}$ and Wayne Hayes ${ }^{a^{*}}$

${ }^{a}$ Department of Chemistry, University of Reading, Whiteknights, Reading, RG6 6AD (UK); Fax: (+ 44) 118-378-6331; Email: w.c.hayes@ reading.ac.uk

${ }^{b}$ Henkel UK Limited, 957 Buckingham Avenue, Slough, SL1 4NL (UK)

${ }^{c}$ Department of Engineering Science, Oxford University, Parks Road, Oxford, OX1 3PJ (UK)

${ }^{d}$ The Reading School of Pharmacy, University of Reading, Whiteknights, Reading, RG6 $6 A D(U K)$

${ }^{e}$ Department of Physics, University of Surrey, Guildford, Surrey, GU2 7XH (UK)

Keywords: supramolecular polymer, self-assembly, polyurethane, phase separation, rheology

\begin{abstract}
This paper reports a systematic study on a series of supramolecular polyurethanes that possess microphase separated morphologies which afford elastic materials at room temperature. Combinations of urea and/or urethane linkers in addition to a phenyl spacer have been used to study the effect of the rigidity of the hard end group segments as well as the hydrogen bonding capability of the urethane-urea linker units. Small angle X-ray scattering (SAXS) experiments have revealed characteristic microphase separated morphologies. Wide angle X-ray scattering (WAXS) was used to probe the lateral packing of the urethane and/or urea within the hard segments. Differential scanning calorimetry (DSC) analysis confirmed that unsymmetrical soft/hard segment phases have been achieved by varying the urethane/urea content. Transmission electron microscopy (TEM) and atomic force microscopy (AFM) determined that a 1-D fibrillar structure was obtained when the hard segment featured ureas whereas a 3-D structure was achieved when a combination of urea and urethane groups was used, giving rise to enhanced elongation properties. Finally, we present mechanical testing data in which oscillatory rheology at a range of frequencies and temperatures has revealed the effect of the connectivity of the hard segments on the relaxation times of the supramolecular chains. Tensile tests showed
\end{abstract}


that end groups with ureas or a combination of a urea and urethane yielded elastic materials with strengths of $c a .5 \mathrm{MPa}$ at room temperature.

\section{Introduction}

Polyurethane and polyurea (PU) based materials[1,2] have found widespread applications in the industrial scale production of synthetic rubbers, adhesives, protective coatings, foams, fibers and elastomers as well as in biomaterials[3,4] and semi-permeable membranes[5]. The extensive use of PUs has been facilitated by their ease of synthesis from relatively inexpensive starting materials[6-8]. In addition, the mechanical properties of PUs are intimately related to their chemical composition[9,10]. The structure/property relationships that exist between the monomeric components and bulk material provide wide scope for tailoring and optimisation of the physical properties of the PUs to target specific applications[11-15].

One of the most intriguing properties of PUs is their elastomeric behaviour[16,17], which arises from the segmented nature of the chemical composition within each polymer chain[18,19]. In the solid state, PUs are observed to phase-separate into soft domains (containing flexible polymeric components) and hard domains which contain a high proportion of urea and/or urethane linkages[9,20,21]. The urea and urethane components are closely associated through hydrogen bonding interactions[2,8,22,23], thereby providing physical crosslinking between the soft segments. Thus these PUs behave similarly to conventional, covalently crosslinked rubbers, except that disruption of the hydrogen bonding by elevating the temperature, permits melt-processing[24].

Yilgör and co-workers have investigated extensively the structure-property relationship in segmented PUs including the local packing of the urea moieties, which results in a high degree of microphase separation[16,25]. In addition, phase separation may be promoted by using apolar soft segments with low surface energies such as polydimethyl siloxane (PDMS)[5,26-28]. During extensive studies by Bouteiller and co-workers[29], PDMS with bis-urea motifs were synthesised, the resulting materials exhibited a 3D network of hard domains, as a consequence of the partial crystallisation of the hard segments. In a related study, Sijbesma and co-workers have investigated[30] the influence of increasing the length of the PDMS soft segments. They found that it was possible to obtain fibrillar 
structures by increasing the incompatibility of the soft and hard segments[31]. Such fibrillar structures were not observed in PUs that contained PEB[32] or PCL[33]. An interesting spherical morphology was observed when longer soft segment chains were used as a result of a transition of cylindrical to micellar ordering along with the enlargement of the volume fraction of the external segment, as predicted by Flory-Huggins[34]. Detailed studies conducted by Thurn-Albrecht et al. have established[35] that for a series of telechelic polyisobutylenes equipped with complementary hydrogen-bonding groups, interactions between micellar aggregates leads to network formation and solid-like properties at lower temperatures induced by gelation without any specific ordering. Recent studies have not just been restricted to low molecular weight polymers with functionalised chain ends, for example Creton et al. have shown that the viscoelastic characteristics of a series poly(n-butyl)acrylates whose central units feature pendant hydrogen bonding motifs can be tailored by the loading of the self-complementary recognition groups[36-37]. Meijer and co-workers have introduced monodisperse hard segments within PUs, and these hard segments were found to undergo crystallisation, and thus achieve a higher degree of microphase separation[38]. It was found that the polymers, which featured two urea groups, displayed a useful balance between high toughness and low melting temperature, the latter of which is key to aiding processability. In agreement with recent studies by Rowan and co-workers[39-41], we have found[42-44] that tough materials could be formed by addition of hydrogen bonding end-groups with low binding constants (between 1 and $45 \mathrm{M}^{-1}$ )[45] to relatively low molecular weight PUs (between 10,000 and 20,000 g/mol). These materials possess interesting temperature responsive properties whereby the degree of phase separation within the materials, and the temperature at which the polymers started to weaken, correlated to the binding constant of the end-group[2,7,22,46,47].

Herein we describe the systematic design and synthesis of four novel, low molecular weight $\left(\mathrm{M}_{\mathrm{n}} \approx 6,600 \mathrm{~g} / \mathrm{mol}, \mathrm{Ð} \approx 1.8\right)$ PUs which vary in the nature of their end-groups. The effect that systematically changing chemical structure and relative $\%$ composition of the hard end group has on the morphology of the new materials has been studied using multiple techniques. In addition we have investigated the mechanical properties of these novel materials by oscillatory rheometry and tensile testing. These extensive studies provide new 
insights into the structure property relationships that underpin this important class of materials.

\section{Results and Discussion}

\subsection{Design}

The aim of this study was to gain a deeper understanding of the relationship between the structure of the end-groups of linear supramolecular PU based materials and resulting morphological and mechanical properties in the solid state. It was predicted that an increase in the rigidity and the number of possible hydrogen bonding interactions within the polymer end-group would generate materials with advantageous rheological properties under ambient conditions, whilst still permitting facile processing at elevated temperatures.

\subsection{Synthesis}

Prior to commencing polymer synthesis, two novel polymer end-groups (1 and 2) were synthesised via a two-step route by initial addition of morpholine derivatives 3 and $\mathbf{4}$ to 4nitrophenyl isocyanate to produce urethane $\mathbf{5}$ and urea $\mathbf{6}$ followed by reduction of the nitro groups (Scheme 1, see also the Supporting Information (SI), Figures S1-8).



Scheme 1. Synthesis of novel end-groups 1 and 2

With the end groups in hand, the targeted supramolecular polymers were generated through a two-step protocol $[8,42,43]$. Briefly, this involves the synthesis of pre-polymer 7 by the addition of MDI to hydroxyl-terminated poly(ethylene-co-butylene) (Krasol) in the bulk state at $120{ }^{\circ} \mathrm{C}(\mathrm{NCO}: \mathrm{OH}$ ratio of 2:1). Subsequent addition of the endgroups (either $\mathbf{1}, \mathbf{2}, \mathbf{3}$ or 4 ) to 7 results in the formation of supramolecular PUs 8, 9, 10 and 11, respectively (Table 1). The supramolecular PUs were isolated in good yields (>84\%) after several precipitations into methanol. 
All four of the supramolecular polymers exhibited comparable molecular weights and polydispersity as measured by GPS analysis $\left(\mathrm{M}_{\mathrm{n}} 6,600 \mathrm{~g} / \mathrm{mol}+/-10 \%\right.$ and $\left.Đ=1.8+/-0.1\right)$. This increase in molecular weight compared to the starting Krasol material $\left(\mathrm{M}_{\mathrm{n}}=1,730\right.$ $\mathrm{g} / \mathrm{mol}, \mathrm{Ð}=1.2$ ) demonstrates that the conditions used to produce the prepolymer 7 result in repeatable degrees of chain extension centred around 3 repeating units of Krasol/MDI.

Table 1. Synthesis and selected properties of polymers 8-11.

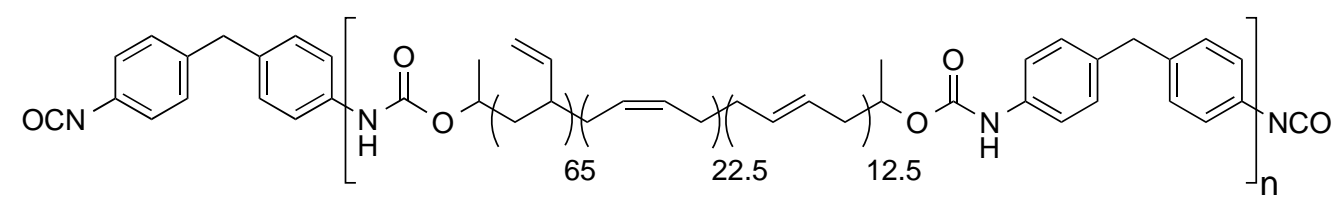

7

dry THF, $80^{\circ} \mathrm{C}, 16 \mathrm{~h}$

$1,2,3$ or 4

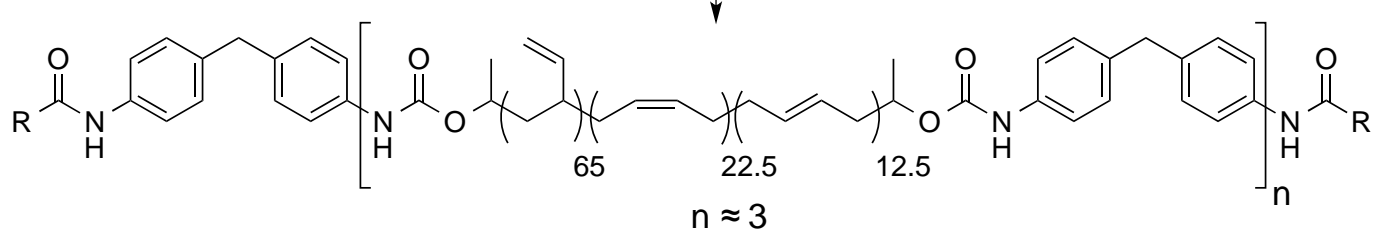

\begin{tabular}{ccccc}
\hline Polymer & $\mathrm{R}$ & $\begin{array}{c}\text { Yield } \\
\%\end{array}$ & $\begin{array}{c}\text { Hard } \\
\text { content }^{\mathrm{a}} \\
\%\end{array}$ & $\begin{array}{c}\text { End- } \\
\text { group }^{\mathrm{b}}\end{array}$ \\
\hline $\mathbf{8}$ & 88 & 17.4 & 3.1 \\
$\mathbf{9}$ & $\mathbf{1 0}$ & 97 & 17.4 & 3.8 \\
\hline
\end{tabular}

${ }^{a}$ calculated as the \%wt/wt of structural components in the polymer that include MDI units as part of the hard segments.

${ }^{b}$ calculated as the $\% w t / w t$ of structural components in the polymer that comprise the terminal MDI units and R groups.

The resulting polymers were structurally related, possessing identical morpholine endgroups but varying numbers of urea groups (see comparison of $\mathbf{8}$ and $\mathbf{9}$ or $\mathbf{1 0}$ and 11), with 
polymers 10 and $\mathbf{1 1}$ featuring two additional urea groups when compared to polymers $\mathbf{8}$ and 9 (see Table 1). Maintaining the composition of the hydrophobic block whilst changing the end group enabled the study of the changes in phase separation on the mechanical properties to be investigated in isolation from changes incurred through altering the soft segments of the PUs.

\subsection{Solid state structures of end group mimics}

In order to provide an insight into how end groups of this type may aid the assembly of polyurethanes in the bulk, the end group mimics 12 and $\mathbf{1 3}$ (Figure 1) were generated (see Figures S17-20) and solid state structures obtained from single-crystal X-ray diffraction analysis (see Figure 1, Table S1 and Figure S21-22).

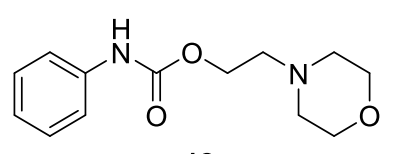

12

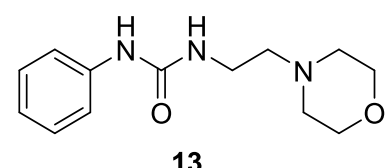

13

Figure 1. End group mimics 12 and $\mathbf{1 3}$

The dominant intermolecular interaction evident for urethane $\mathbf{1 2}$ was found to be a strong hydrogen bond $\left(2.142 \AA\right.$ and $\left.139.73^{\circ}\right)$ between the morpholine oxygen and urethane hydrogen (see Figure 2a) whereas bifurcated hydrogen bonds [48] between urea moieties dominated in the solid state structure of urea $\mathbf{1 3}$ as shown (see Figure 2b). 
A

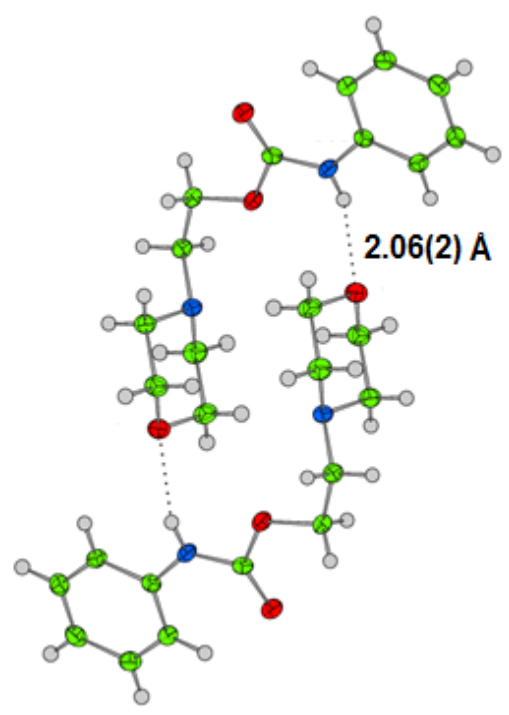

B



Figure 2. Single-crystal X-ray diffraction analysis of a) urethane 12 and b) urea 13

\subsection{Morphology}

Variable temperature SAXS has revealed that each member of the series of supramolecular polymers (8-11) exhibited phase separation (see Figure S23 and 24)[45,49,50]. The Bragg spacing associated with the phase separation was found to be $5.18 \mathrm{~nm}, 5.71 \mathrm{~nm}, 7.12 \mathrm{~nm}$ and $7.19 \mathrm{~nm}$ for 8-11, respectively. It can be seen that a small increase in the hard group content from 17 to $20 \%$ (from 8-9 to 10-11, respectively) resulted in a dramatic increase in $\mathrm{d}$ spacing (at least $1.5 \mathrm{~nm}$ ). For each pair of polymers with the same hard-group content (8-9 and 10-11), the substitution of a more strongly hydrogen bonding urea group in place of a urethane resulted in a subtle increase in spacing.

Time resolved SAXS analysis was conducted on each polymer (8-11), acquiring a scattering pattern every 30 seconds as the samples were heated from $-70{ }^{\circ} \mathrm{C}$ to $70{ }^{\circ} \mathrm{C}$ and then returned to $-70{ }^{\circ} \mathrm{C}$ (heating and cooling rate $5{ }^{\circ} \mathrm{C} / \mathrm{min}$ ) (see Figure S25). Each sample presented a single Bragg reflection in the SAXS patterns, typical of the phase-separated morphology of PUs. Qualitative analysis of the SAXS patterns for the polymers 8 to 11 sequentially revealed that on increasing temperature, the intensity increases slightly up to $0{ }^{\circ} \mathrm{C}$ for samples $\mathbf{8}$ and $\mathbf{9}$ and then decreases markedly. In contrast, for samples $\mathbf{1 0}$ and $\mathbf{1 1}$ 
the intensity increases continuously up to at least $50{ }^{\circ} \mathrm{C}$. Comparing the SAXS data for 8 and $\mathbf{9}$ which contain the more weakly associating end groups with $\mathbf{1 0}$ and $\mathbf{1 1}$ (which contain an increased number of strongly hydrogen bonding urea residues) shows a clear increase in the phase contrast as the hydrogen bonding potential of the end-groups increases.

For the polymers with the lower hard block content (i.e. 8 and 9), the intensity of the primary peak decreased with increasing temperature, above $0{ }^{\circ} \mathrm{C}$ (see Figure $\mathrm{S} 23$ and Figure S24), suggesting an increase in miscibility between the end-groups and the mid blocks as the temperature rises. Conversely, for polymers $\mathbf{1 0}$ and 11, the domain spacing increased slightly with temperature. As observed previously[29], this may be accounted for by stronger hydrogen bonding interactions within the larger end groups, maintaining the integrity of the hard blocks over the temperature range studied. Thus, the hard domains remain intact whilst the soft domains undergo thermal expansion, increasing the domain spacing at higher temperatures. It is also not unreasonable to expect the hydrogen bonding distances between the hard blocks to expand as the temperature of the environment increases. This trend is consistent with the observation that the temperature at which each polymer exhibits the maximum in its domain spacing increases in the order 8-11, (from 0 ${ }^{\circ} \mathrm{C}$ for $\mathbf{8}$ to $>70{ }^{\circ} \mathrm{C}$ for 11 ) indicating that disruption of the hard segments occurs at higher temperatures. The temperature dependence of this molecular-scale packing is observed readily in a plot of the intensity of the Bragg peak as a function of temperature. It can be seen that for all polymers (8-11) the d spacing increases with temperature, consistent with the thermally induced dissociation of the end-groups (Figure 3). The WAXS data in Figure 3 shows a clear increase in the d spacing with temperature for all samples (the full WAXS profiles are shown in Figure S26). This distance reflects side-to-side packing of molecules. 


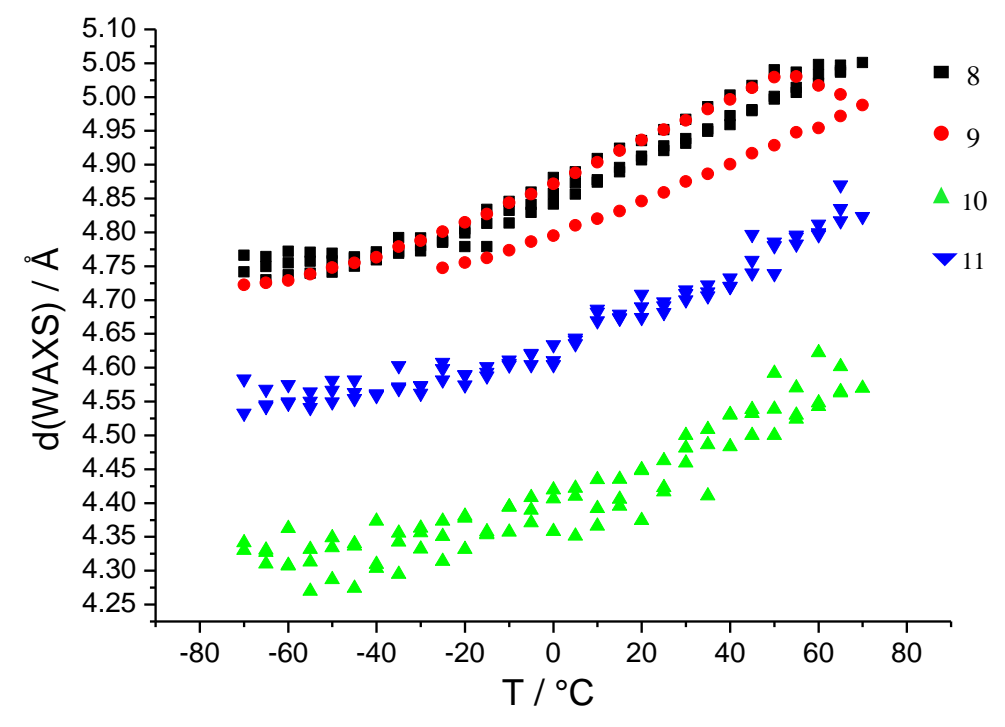

Figure 3. Summary of the temperature-dependent WAXS d spacing revealing local packing spacing of end-capped polymers 8-11.

Comparison of the WAXS scattering signals for each of the polymers at $25^{\circ} \mathrm{C}$ revealed more information about the packing within the hard domains (Figure 4). Polymers 8 and $\mathbf{9}$, with the lower hard block content give a broad scattering signal with maxima at $4.98 \mathrm{~nm}$ and $4.92 \mathrm{~nm}$, respectively, consistent with an amorphous system. In contrast, in the case of polymers $\mathbf{1 0}$ and 11, three sharp signals are evident in their WAXS patterns at ca. 4.6, 4.2 and $3.5 \AA$. These well-resolved reflections demonstrate the presence of regions with a certain degree of ordering, which may be attributed to urea and urethane lateral spacing (4.6 and $4.2 \AA$ ) and $\pi-\pi$ stacking $(3.5 \AA)[51]$ as a consequence of the aromatic spacer unit within these end-groups. 


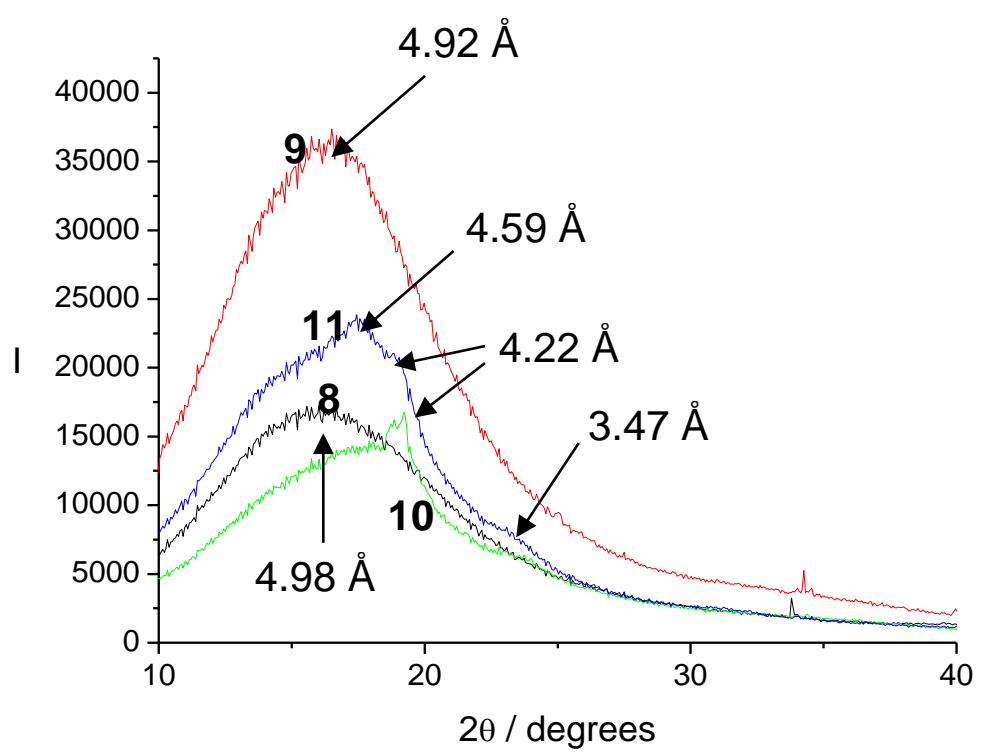

Figure 4. WAXS scattering patterns of 8-11 at $25^{\circ} \mathrm{C}$

Analysis of the DSC thermograms for each of the polymers (8-11) supports the X-ray scattering analysis and indicates the amorphous nature of $\mathbf{8}$ and 9 ( $\mathrm{ca} .17 \%$ hard block composition) whereas broad peaks can be seen for polymers 10 and $\mathbf{1 1}$ ( $c a .20 \%$ hard block composition) suggesting that they are partly amorphous (Figure 5).



Figure 5. DSC thermograms for the polymer series 8-11. The data shown was obtained during the second heating ramp at a heating rate of $10^{\circ} \mathrm{C} / \mathrm{min}$. 
Increasing hard segment content produced two notable effects, firstly, a modest decrease in the $\mathrm{T}_{\mathrm{g}}$ of the soft segment (from $c a .-30{ }^{\circ} \mathrm{C}$ for $\mathbf{8}$ and 9 to $c a .-35^{\circ} \mathrm{C}$ for $\mathbf{1 0}$ and 11). The broad appearance of this transition, which can extend to approximately $0{ }^{\circ} \mathrm{C}$ may be as a consequence of the relatively disperse nature $(Đ \approx 1.8)$ of these samples. Secondly, the appearance of distinct transitions for the hard segments of polymers which contained the more extended end-groups (10 and 11). These higher temperature thermal transitions (maxima $c a \cdot 190-200{ }^{\circ} \mathrm{C}$ ) are thought to correspond to dissociation of the non-covalent bonds between the polymer end-groups. In addition, these findings indicate a well-defined microphase separation in these two polymers (10 and 11)[52]. In contrast, the thermograms of polymers 8 and $\mathbf{9}$ show a continuous decrease in heat flow at higher temperatures. These transitions may be attributed to the formation of two compositionally distinct hard block domains comprising primarily either urea or urethane moieties[29].

The homogeneous morphology of the starting homopolymer shown by AFM (Figure S27) confirms the absence of microphase segregation. The urethane $\mathbf{8}$ also exhibits no phase separation and the AFM appears very similar to that of the un-endcapped mid-block polymer (Figure S27). In contrast, the interchange of the urethane linkage for a urea in 9 produced a phase-separated morphology revealed by both AFM and TEM analysis (see Figure S28). The AFM micrograph of 9 (see Figure S28a) reveals the different domains produced by the immiscibility of block components when compared with the characteristic monophase of the unendcapped polymer. In addition, TEM analysis confirmed the existence of microphase separated structure (see Figure S28b). The well-defined morphology observed in Figure S28 corroborates the capacity of ordering attributed to bisurethane/urea system. The pre-organised arrangement adopted by the rigidity of the endgroups promotes the ordered stacking of the urethane/urea units. The morphology featured in 10 and 11 consists of the hard segment (in bright) surrounded by the soft segment matrix (dark)[30]. The phase separation of the hard/soft segments is pronounced for polymers 10 and 11 (Figure 6) which is in agreement with the DSC data obtained (Figure 5). Interestingly, the striking differences between the morphologies of $\mathbf{8}$ and $\mathbf{9}$ (see Figures S27 and S28) and those of $\mathbf{1 0}$ (Figure 6a and Figure 6b) and $\mathbf{1 1}$ (Figure 6c and Figure 6d) were generated by a minimal increase ( $c a .3 \mathrm{wt} \%)$ of the hard content. 
a

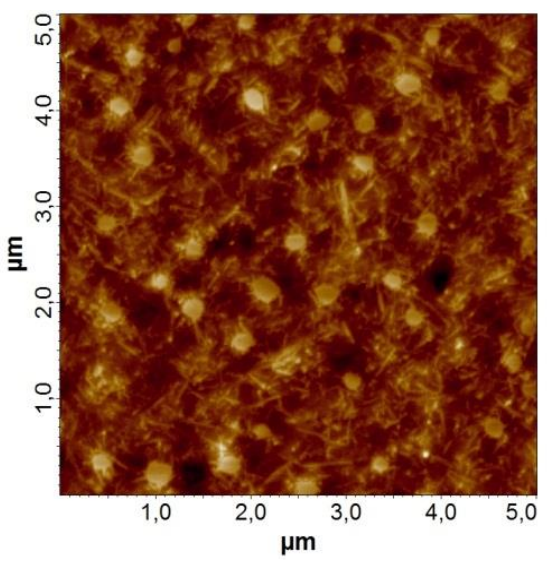

c

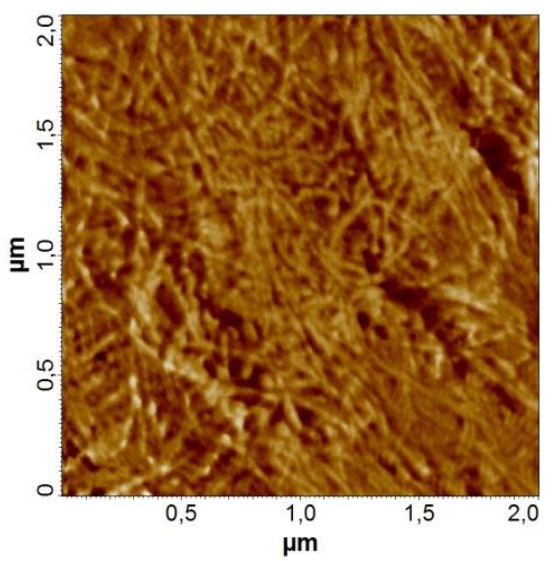

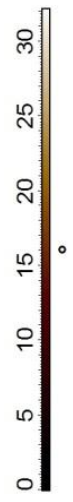

b

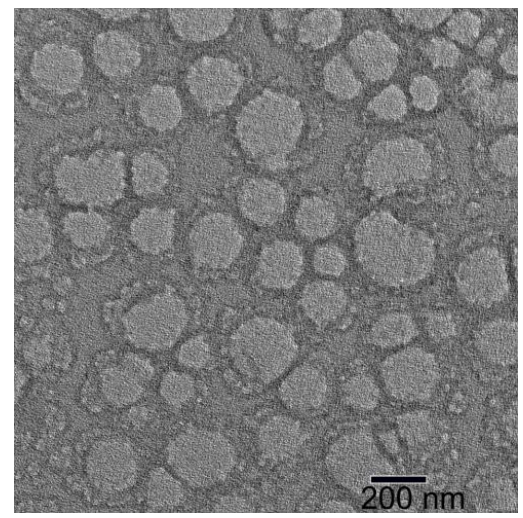

n d

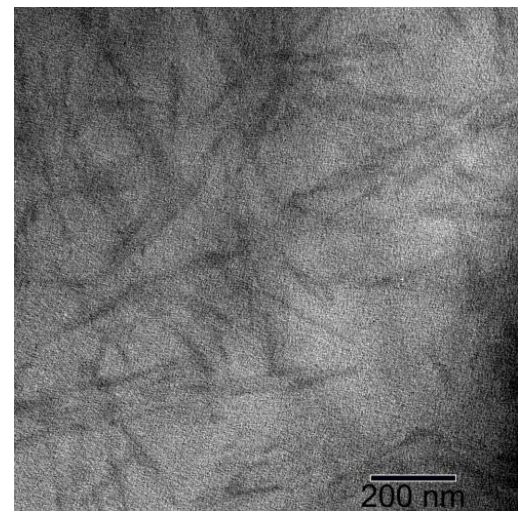

Figure 6. a) AFM and b) TEM image of morpholine terminated urethane polybutadiene derivative 10; c) AFM and d) TEM image of morpholine terminated urea polybutadiene derivative $\mathbf{1 1}$

It has been shown that PUs aggregate in the bulk in hard domains with dimensions $c a .300$ $\mathrm{nm}$, referred to as 'urea balls' (as observed in this study with polymer 10, Figure 6a)[51]. The fibrillar structure featured by $\mathbf{1 1}$ is consistent with the strength of the local packing of the urea groups in contrast with less ordered association of the urethane end groups. AFM analysis of 11 revealed assemblies of fibres (67.5 $\mathrm{nm}$ thick on average) which were also densely packed. The fibres formed by $\mathbf{1 1}$ appear to be ribbon-like[18]. The fibrillar structure obtained suggests that the hard hydrogen bonded domains are separated by the soft apolar segments, indeed this data correlated with the variable temperature SAXS analysis which revealed a broad peak centred at $7.5 \mathrm{~nm}$. Higher order peaks are not present, which shows the absence of a long-range ordered morphology such as hexagonal-packed cylinders. In contrast to polymer 11, 10 does not form well-defined (fibrillar) aggregates 
but exhibits an irregular phase-separated morphology with rounded domains (Figure 6)[51]. The difference in morphology is remarkable and is ascribed to differences in hydrogen-bonding interactions between the end groups (as shown by the WAXS data in Figure 4) which has a substantial effect on the phase separation morphology.

\subsection{Mechanical characterisation}

Mechanical characterisation was performed using rheometry, dynamic mechanical analysis (DMA) and tensile tests. The rheological behaviour of $\mathbf{8}$ and 9 was compared to the domain spacing evolution with temperature in Figure 7 (Figure S29). Temperature dependent changes in microstructure were observed to be consistent with the mechanical response. In particular, the onset of phase coalescence coincides with a transition in the rheological behaviour of the materials. This result suggests that in the case of $\mathbf{8}$ and $\mathbf{9}$ the onset of phase coalescence coincides with a transition in the rheological behaviour of the materials. This result suggests that the observed decrease in storage modulus versus temperature is related to phase mixing and to the dissociation of secondary bonds between the end-groups of the polymers[8]. Isothermal frequency sweeps were also performed and timetemperature superposition used to produce master curves presented in the SI (Figure S29), along with the shift factor as a function of temperature.

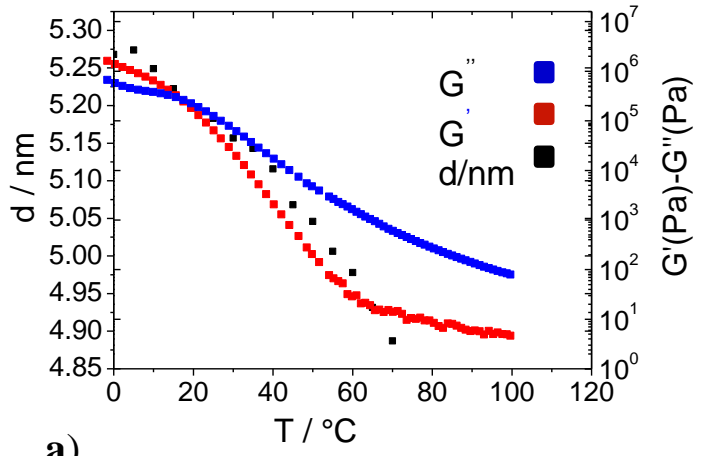

a)

Figure 7. $G^{\prime}, G^{\prime \prime}$ and domain spacing of morpholine terminated polybutadiene derivative against temperature and for materials: a) 8 and b) 9 Data obtained in oscillatory shear at a frequency of $10 \mathrm{~Hz}$ and cooling rate of $3{ }^{\circ} \mathrm{C}$ per minute.

A 'melting temperature' was defined as the temperature above which the storage modulus falls below 0.1 MPa. This temperature increased from $38^{\circ} \mathrm{C}$ for 8 to $53{ }^{\circ} \mathrm{C}$ for $\mathbf{9}$, as a direct 
result of the stronger hydrogen bonding between the urea groups of compound 9. In contrast, examination of the plots of the storage modulus versus temperature of $\mathbf{1 0}$ and $\mathbf{1 1}$ did not reveal any transition in their rheological behaviour over this temperature range (Figure 8$)$. The materials remained solid within the entire temperature range studied $(0-$ $120^{\circ} \mathrm{C}$ ) with storage moduli in the order of $1-10 \mathrm{MPa}$ (Table 2). It is noted that even after a further increase of the temperature to $200{ }^{\circ} \mathrm{C}$, a rheological transition was not observed for these materials.



Figure 8. Shear storage modulus versus temperature for molecules tested in oscillatory shear at a frequency of $5 \mathrm{~Hz}$ and a cooling rate of $2{ }^{\circ} \mathrm{C}$ per minute.

Table 2. Rheology data for polymers $\mathbf{8 , 9}, \mathbf{1 0}, \mathbf{1 1}$, E' was calculated as $3 \times \mathrm{G}^{\prime}$, assuming incompressibility

\begin{tabular}{lllll}
\hline & $\mathbf{8}$ & $\mathbf{9}$ & $\mathbf{1 0}$ & $\mathbf{1 1}$ \\
\hline Melting point $\left[{ }^{\circ} \mathrm{C}\right]$ & 38 & 53 & - & - \\
$\mathrm{E}^{\prime}\left(20^{\circ} \mathrm{C}\right)[\mathrm{MPa}]$ & 2.5 & 7.2 & 32 & 55 \\
\hline
\end{tabular}

DMA was employed to further probe the mechanical response of three of the materials $(\mathbf{8}$, 9, 11) at low temperatures. As shown in Figure 9, at temperatures below about $0{ }^{\circ} \mathrm{C}$, the compounds present the standard viscoelastic behaviour of high molecular weight polymers. A glassy region is followed by the glass transition, with a $\mathrm{T}_{\mathrm{g}}$ (taken at the maximum of tan $\delta$ ) of around $-10{ }^{\circ} \mathrm{C}$ common for all three materials. This finding is consistent with DSC results that showed the $T_{g}$ of $\mathbf{1 1}$ to be only slightly lower than that of $\mathbf{8}$ and $\mathbf{9}$. Of note is the lower max tan $\delta$ value of $\mathbf{1 1}$ when compared to $\mathbf{8}$ and $\mathbf{9}$. This higher degree of elasticity in $\mathbf{1 0}$ could be associated with a more developed elastic-network for this compound or with 
the presence of a crystalline phase. At temperatures above $0{ }^{\circ} \mathrm{C}$, two distinctly different behaviours were observed. 11 showed a wide rubbery plateau, with storage modulus in the order of around $100 \mathrm{MPa}$ and no sign of melting up to $80^{\circ} \mathrm{C}$. On the other hand, the storage modulus of $\mathbf{8}$ and $\mathbf{9}$ never reached a plateau. Instead, beyond the glass transition, E' continued to decrease with increasing temperature, albeit at a slower rate, up to an apparent melting point at about 20 to $30{ }^{\circ} \mathrm{C}$. These findings confirm the results from parallel plate oscillatory shear rheometry, and demonstrate the effect of increasing the strength of noncovalent interactions between the PU chains. From a practical point of view, it is desired that the compounds have a broad rubbery plateau followed by a sharp melting transition, to ensure a stable mechanical response, while maintaining processability.
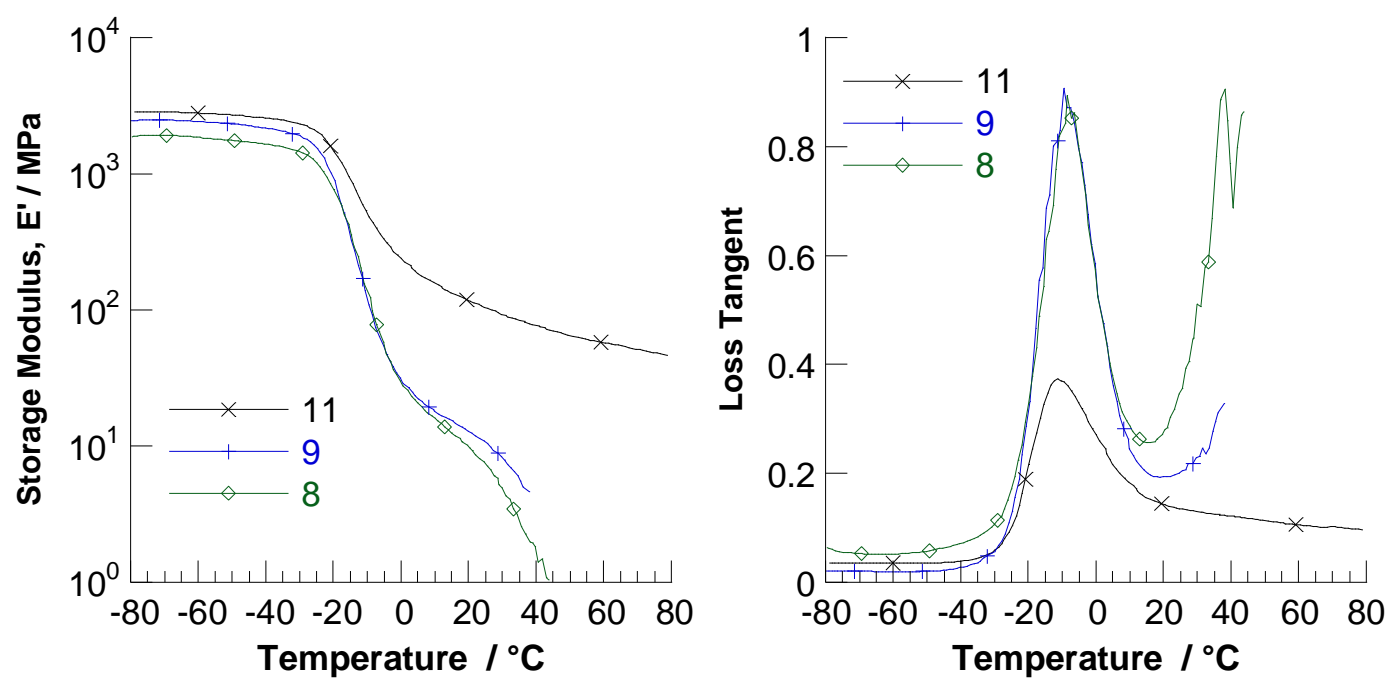

Figure 9. Tensile storage modulus (left) and loss tangent (tan $\delta$, right) versus temperature for polymers $\mathbf{8 , 9}$ and 11 .

The mechanical properties of the materials were explored further by tensile testing at room temperature and a constant true strain rate of $0.04 \mathrm{~s}^{-1}$. At least five samples were tested for each material. Typical stress versus strain traces of 9, 10 and $\mathbf{1 1}$ are shown in Figure 10, note that data for $\mathbf{8}$ are not shown because it produced a low quality film that could not be tested reliably to failure. The failure strain and ultimate tensile strength (UTS) of the materials are shown in Table 3. As evidenced by the rheometer data, the addition of the aromatic rings to the end-groups of the compounds results in a significant increase in 
stiffness. Here, the tensile modulus (measured as the slope of the true stress versus true strain plots between $0.2 \%$ and $0.8 \%$ strain) increases from $2.5 \mathrm{MPa}$ in the case of 9 to around $85 \mathrm{MPa}$ for 10 and $55 \mathrm{MPa}$ for $\mathbf{1 1}$. At the same time the true strain at the point of failure decreases dramatically (from 1.3 for 9 to 0.1 for 10) while the UTS increases from approximately $0.2 \mathrm{MPa}$ for 9 to around $5 \mathrm{MPa}$ for $\mathbf{1 0}$ and $\mathbf{1 1}$. These results can be interpreted by considering the strength of intermolecular non-covalent bonds. In the case of compound 9 the dissociation of the relatively weak hydrogen bonds at low loads is followed by chain sliding up to the point of rupture. However, it is proposed that the stronger non-covalent bonds in the case of $\mathbf{1 0}$ and $\mathbf{1 1}$ act as effective cross-link points that remain intact during loading which would give rise to a different failure mechanism where the chains are first stretched and subsequently the network is broken.



Figure 10. True stress versus true strain tensile plots for $\mathbf{9 , 1 0}$ and $\mathbf{1 1}$

Table 3. Tensile properties for polymers $\mathbf{9 ,} \mathbf{1 0}$ and $\mathbf{1 1}$

\begin{tabular}{llll}
\hline & $\mathbf{9}$ & $\mathbf{1 0}$ & $\mathbf{1 1}$ \\
\hline Modulus [MPa] & $2.5 \pm 0.2$ & $86.7 \pm 3.6$ & $55.1 \pm 2.3$ \\
Failure true strain & $1.33 \pm 0.20$ & $0.10 \pm 0.04$ & $0.20 \pm 0.06$ \\
UTS [MPa] & $0.2 \pm 0.0$ & $5.0 \pm 0.7$ & $5.4 \pm 0.4$ \\
\hline
\end{tabular}

\section{Conclusion}

We have studied the morphology of a series of novel supramolecular polyurethanes that differ by hard end group content ( $\mathrm{ca} .17$ or $20 \%$ ) and the chemical composition (urea or urethane) of the end group. Studies of the solid state structures of small molecule analogues 
of the urea and urethane end groups were conducted. These showed that the dominant intermolecular interaction for urethane was a hydrogen bond between the morpholine oxygen and urethane hydrogen, whereas the urea small molecule exhibited a stronger bifurcated hydrogen bond. The morphology of the novel polymers containing these end groups was studied in detail using multiple techniques. Small angle X-ray scattering (SAXS) experiments have revealed that the polymer $\mathbf{8}$ containing the weakly hydrogen bonding urethane end groups and the lower hard end group content did not form phase separated materials. However, increasing the hydrogen bonding capability of the end group by replacing a urethane with a urea linkage resulted in characteristic microphase phase separated materials. WAXS analysis of the materials showed that order within the hard segments increased with increasing hydrogen bonding strength of the end groups and increasing hard end group content. This was supported by DSC analysis which revealed varying the urethane/urea content resulted in unsymmetrical soft/hard segment phases. TEM and AFM confirmed the lack of phase separation in the low hard end group content urethane containing polymer (8). However, TEM and AFM determined that a 1-D fibrillar structure was obtained when the hard segment featured a urea (9) whereas the high hard end group content materials (10 and 11) exhibited a highly ordered 3-D morphology. The morphology of the materials had a direct effect on the mechanical properties of the polymers. Urethane $\mathbf{8}$ could not be cast into coherent films suitable for testing. However, urea 9 with its phase separated morphology was a low tensile modulus (2.5 MPa), ductile material (failure true strain $=1.33$ ). The two polymers with the higher hard end group content and extensive 3D interconnected morphology (10 and 11) were an order of magnitude stiffer (E>55 MPa) but also an order of magnitude less ductile (failure true strain $<0.2)$ than 9.

\section{Experimental}

\section{Materials}

The reagents used were commercially available from either Acros Chimica, Aldrich Chemical Company or Alfa Caesar and were used without further purification. The dry solvents involved in the project were bought and used as supplied or distilled with appropriate dehydration agents i.e. tetrahydrofuran (THF) which was distilled from 
benzophenone and sodium. All other reagents such as polybutadiene Krasol LBH2000; $\overline{\mathbf{M}}_{\mathrm{n}}$ (1730) and $\overline{\mathrm{M}}_{\mathrm{w}}$ (2020); $\overline{\mathrm{M}}_{\mathrm{w}} / \overline{\mathrm{M}}_{\mathrm{n}}$ (1.17); concentration of hydroxyl groups (1.021meq.g 21); and isomer content (60 wt\% of 1,2-;15 wt $\%$ of 1,4-cis, and $25 \mathrm{wt} \%$ of 1,4-trans), and 4,4'-methylenebis(phenylisocyanate) were supplied by Henkel Adhesive Technologies, Slough, UK.

Thin-layer chromatography (TLC) was performed on aluminium sheets coated with Merck silicagel $60 \mathrm{~F}_{254}$. Column chromatography was performed using either SI60 sorbent silica (40-63 $\mu \mathrm{m})$ supplied from VWR international or Brockmann 1, standard grade, neutral activated aluminium oxide ( $c a .150$ mesh) supplied from Aldrich Chemical Company.

\section{Instrumentation}

${ }^{1} \mathrm{H}$ Nuclear magnetic resonance spectroscopy $\left({ }^{1} \mathrm{H}-\mathrm{NMR}\right)$ was conducted on either a Bruker DPX250 (250 MHz), a Bruker AMX400 $(400 \mathrm{MHz})$ or a Bruker DPX400 (400MHz) spectrometers using the deuterated solvent as the lock. In the same manner, ${ }^{13} \mathrm{C}$ Nuclear magnetic resonance spectroscopy $\left({ }^{13} \mathrm{C}-\mathrm{NMR}\right)$ was performed on a Bruker DPX250 (62.5 MHz), a Bruker AMX400 (100 MHz) or a Bruker DPX400 (100MHz) spectrometers. Infrared spectroscopy was performed using a Perkin Elmer 1420-X spectrometer with the samples analysed as either neat films or in solution between two potassium bromide or sodium chloride disks.

Bruker MicroToF LCMS has been utilised in order to obtain Mass spectrometry analysis with ionisation via electrospray and samples injected by direct insertion via a syringe pump. Electrothermal digital melting point instrument or DSC on a TA Instruments DSC Q2000 differential scanning calorimeter were used to find out the melting point of the SPUs. The average molecular weight of the polymers generated was determined via Gel Permeation Chromatography (GPC) Polymer Laboratories PL-GPC 220 high temperature chromatograph fitted with PL Mixed Gel columns at $40{ }^{\circ} \mathrm{C}$. The samples were dissolved in analytical grade chloroform $(5 \mathrm{mg} / \mathrm{mL})$, and analysed against PL Easy-Cal Polystyrene as the calibrants.

AFM experiments have been carried out at Surrey University in collaboration with Professor Joe Keddie and Dan Liu using a NT-MDT instrument (Russia) in tapping mode, the tip spring constant was $c a .9 .8 \mathrm{~N} / \mathrm{m}$ and the frequency was $180 \mathrm{KHz}$. The samples were directly drop casted from a solution of $1 \%$ (w/v) on a mica sheet placed on the AFM holder. 
The mica sheet was cleaved with adhesive tape before the sample was placed on the mica surface. The samples were also spin-coated in a silicon wafer from the same solution $1 \%$ $(w / v)$ in THF.

TEM analysis was performed in the Centre for Advance Microscopy at the University of Reading (CFAM) using a CM20 Transmission Electron Microscope with an electron beam voltage of $80 \mathrm{kV}$ with assistance of Dr Peter Harris. Sample preparation on carbon grids (S162-3 Formvar/Carbon $300 \mathrm{Mesh} \mathrm{Cu}$ ) consisted of placing a droplet of the sample onto the grid and allowing the grid to dry in air. The sample was then stained with a droplet of uranyl acetate (1\% in water) and left to dry in air prior to analysis.

SAXS/WAXS experiments were conducted at station BM26B of the European Synchrotron Radiation Facility (ESRF) in Grenoble (France). The samples were introduced in pans DSC 600 heating stage from Linkam that were previously pierced in order to produce X-ray windows. The windows are made of mica and the capsules were sealed avoiding sample loss. DSC runs are performed to study the thermal dependency of the interaction between the self-assembled polyureas and polyurethanes as well as the physical properties associated to the bisurethane systems [53]. The distance to the SAXS detector was $c a .5 \mathrm{~m}$ using a wavelength of $0.145 \mathrm{~nm}$. A-2D multiwire detector with a resolution of $512 \times 515$ pixels and a pixel size of $260 \mu \mathrm{m}^{2}$. Standard corrections for sample absorption and background subtraction have been performed. WAXS images were recorded using a CCD-based X-ray digital camera (Photonic science) with a pixel size of $44 \mu \mathrm{m}^{2}$.

Thin films of the polyurethanes were produced for mechanical testing via a solution casting procedure. All of the polyurethanes were dissolved in THF and the solution was poured into flat PTFE molds. This was subsequently placed in a vacuum oven at $70{ }^{\circ} \mathrm{C}$ with a pressure of approximately 0.6 to 0.8 bar for a duration of 24 hours. Polyurethane films of uniform thickness between 200 and $500 \mu \mathrm{m}$ were obtained at the end of this procedure without residual solvent. Rheological analysis was performed on circular samples ( $25 \mathrm{~mm}$ diameter) that were obtained from the moulded film using a steel punch cutter. For tensile testing, rectangular samples were cut with a razor blade and paper end-tabs were bonded to the samples with a commercial cyanoacrylate adhesive Loctite ${ }^{\mathrm{TM}}$. This sample assembly was found to reduce slippage inside the tensile grips of the tensometer. The gauge section between the grips was of $25 \mathrm{~mm}$ length, $5 \mathrm{~mm}$ width and approximately $0.5 \mathrm{~mm}$ thickness. 


\section{Mechanical testing}

Rheometry was performed on two machines, both using parallel plate oscillatory shear. Data in Figures 7 and S32 were obtained using a TA instruments AR2000 rheometer. Temperature sweeps were performed at a single frequency of $10 \mathrm{~Hz}$ with a strain amplitude of $0.1 \%$. Initially, the samples were placed on the rheometer, heated to $100{ }^{\circ} \mathrm{C}$ and held to one hour. Then, the temperature was decreased to $-50{ }^{\circ} \mathrm{C}$ at a rate of $3{ }^{\circ} \mathrm{C}$ per minute whilst data were collected. For the isothermal frequency sweeps, the samples were again placed in the rheometer and heated to $70^{\circ} \mathrm{C}$ for approximately 5 minutes. The temperature was reduced to $20^{\circ} \mathrm{C}$, and again held for 5 minutes. The frequency sweeps were the performed between 0.1 and $100 \mathrm{rad} / \mathrm{s}$ at a strain amplitude of $0.1 \%$ for each selected temperature, each time the temperature was held for 5 minutes before data were gathered. Three cycles of tests were measured, and the results show that the repeating heating does not change the properties significantly (SI).

Experiments reported in Figure 8 were performed with an Anton Paar Physica MCR 301 rheometer. For the temperature sweep at a single frequency of $5 \mathrm{~Hz}$ and a strain amplitude of $0.1 \%$, the samples were placed on the rheometer, heated to $70{ }^{\circ} \mathrm{C}$ and held at this temperature for approximately 5 minutes. The samples were then subjected to a cooling temperature ramp of $2{ }^{\circ} \mathrm{C} / \mathrm{min}$ to $0{ }^{\circ} \mathrm{C}$ before being heated up to $120^{\circ} \mathrm{C}$ and held at this temperature for 1 hour. After this step they were cooled again from $120{ }^{\circ} \mathrm{C}$ to $0{ }^{\circ} \mathrm{C}$ at 2 ${ }^{\circ} \mathrm{C} / \mathrm{min}$. During all of these steps the dynamic shear moduli $\left(\mathrm{G}^{\prime}, \mathrm{G}^{\prime \prime}\right.$ and $\tan \delta$ ) of the samples were recorded. This method was applied to ensure that chemical cross-linking had not occurred during the exposure of the samples to high temperatures. Cross-linking was not observed, i.e. an increase in $\mathrm{G}^{\prime}$ during the isothermal step at $120^{\circ} \mathrm{C}$ was not observed. Dynamical mechanical analysis (DMA) was performed with a TA Q800 DMA, in tensile mode. The samples were subjected to a heating ramp from $-80^{\circ} \mathrm{C}$ up to $80{ }^{\circ} \mathrm{C}$ at a rate of 2 ${ }^{\circ} \mathrm{C}$ per minute. Dynamic tension was applied at a frequency of $5 \mathrm{~Hz}$ and a strain amplitude of $0.1 \%$. To avoid buckling, a ratio of static to dynamic force of $120 \%$ was maintained throughout each test.

The tensile testing was carried out on an Instron universal testing machine (model 5982) with a $100 \mathrm{~N}$ load cell. A constant true strain rate of $0.04 \mathrm{~s}^{-1}$ was used, for the purposes of 
controlling the experiment (but not subsequent data analysis) this was calculated from the cross-head displacement. Strains for data analysis were calculated from digital image correlation. A fine speckle pattern was sprayed onto the specimen surface and imaged during the experiment using a digital camera. The images were analysed using commercial image analysis software (DaVis V8, LaVision) to produce specimen strains.

\section{X-ray Structure Determination}

Crystals of 12 and 13 were mounted under Paratone-N oil and flash cooled to $150 \mathrm{~K}$ under nitrogen in an Oxford Cryosystems Cryostream. Single-crystal X-ray intensity data were collected using an Agilent Gemini S Ultra diffractometer $(\mathrm{Cu} K a ́$ radiation $(\ddot{\mathrm{e}}=1.54180$ $\AA$ ) or Mo Ká radiation ( $\ddot{\mathrm{e}}=0.71073 \AA$ ). The data were reduced within the CrysAlisPro software [54]. The structures was solved using the program SIR92[55] and all nonhydrogen atoms located. Least-squares refinements on $F$ were carried out using the CRYSTALS suite of programs[56]. The non-hydrogen atoms were refined anisotropically. All the hydrogen atoms were located in difference Fourier maps, then those attached to $\mathrm{C}$ were placed geometrically with a $\mathrm{C}-\mathrm{H}$ distance of $0.95 \AA$ and a $U$ iso of 1.2 times the value of $U_{\text {eq }}$ of the parent $\mathrm{C}$ atom. The fractional coordinates of the $\mathrm{H}$ atoms attached to the $\mathrm{N}$ atoms were refined freely whilst those of the hydrogen atoms attached to $\mathrm{C}$ were then refined with riding constraints. All crystals of compound $\mathbf{1 3}$ were found to be racemic twins.

\section{Synthesis of 2-morpholinoethyl 4-nitrophenylcarbamate 5}

To a stirred solution of nitrophenylisocyanate $(4.00 \mathrm{~g}, 24.4 \mathrm{mmol})$ in THF $75 \mathrm{~mL}$ under nitrogen was added $\mathrm{N}$-(2-hydroxylethyl)-morpholine (3.52 mL, $26.8 \mathrm{mmol})$ dropwise from a syringe. After 18 hours at room temperature the solvent was removed under reduced pressure to leave a sticky yellow solid. Trituration in hexane $(50 \mathrm{~mL})$ afforded the target urethane as a yellow powder $(6.20 \mathrm{~g}, 86 \%)$. Recrystallization from EtOAc $(50 \mathrm{~mL})$ and methanol $(17 \mathrm{~mL})$ of a portion from chloroform produced orange crystals suitable for Xray crystallographic analysis. m.p. $=108-109^{\circ} \mathrm{C}$; IR (thin film) $U_{\max } / \mathrm{cm}^{-1} 3265,3087,2860$, 2822, 1738, 1613, 1596, 1555, 1504, 1454, 1414, 1333, 1304, 1223, 1177, 1112, 1067 , 941, 854, 751, 690, 531; ${ }^{1} \mathrm{H}$ NMR (250 MHz, $\left.\mathrm{CDCl}_{3}\right) \delta 2.53(4 \mathrm{H}, \mathrm{t}, J=4.1), 2.69(2 \mathrm{H}, \mathrm{t}, J$ = 5.6), $3.74(4 \mathrm{H}, \mathrm{t}, J=4.6), 4.34(2 \mathrm{H}, \mathrm{t}, J=5.6), 7.22(1 \mathrm{H}, \mathrm{s}), 7.55$ (2H, AA'XX' system, $J=9.1), 8.20\left(2 \mathrm{H}, \mathrm{AA}^{\prime} \mathrm{XX} X^{\prime}\right.$ system, $\left.J=9.1\right) ;{ }^{13} \mathrm{C} \mathrm{NMR}\left(62.5 \mathrm{MHz}, \mathrm{CDCl}_{3}\right) \delta 53.8,57.3$, 
62.3, 66.8, 117.7, 125.2, 143.1, 143.9.0, 152.7; $\left(\mathrm{NCO}_{2}\right.$; MS (CI) calc. for $\mathrm{C}_{13} \mathrm{H}_{17} \mathrm{~N}_{3} \mathrm{O}_{5}$ : 295.1168 , found 295.1169.

\section{Synthesis of 1-(2-morpholinoethyl)-3-(4-nitrophenyl)urea 6}

Synthesis of nitro urea $\mathbf{6}$ was achieved by the addition of 4-(2-aminoethyl)morpholine (3.52 $\mathrm{mL}, 26.8 \mathrm{mmol})$ to 4-nitrophenyl isocyanate $(4.00 \mathrm{~g}, 24.4 \mathrm{mmol})$ following the procedure detailed for 5 to give $\mathbf{6}$ as an orange powder $(6.05 \mathrm{~g}, 84 \%)$. m.p. 191-194 ${ }^{\circ} \mathrm{C}$; IR (thin film) $\mathrm{U}_{\max } / \mathrm{cm}^{-1} 3335,2946,2817,1675,1598,1552,1502,1329,1300,1255,1224,1110,850$, 751; ${ }^{1} \mathrm{H}$ NMR (400 MHz, $\left.\mathrm{CDCl}_{3}\right) \delta 2.52(4 \mathrm{H}, \mathrm{t}, J=4.4), 2.57(2 \mathrm{H}, \mathrm{t}, J=5.6), 3.40(2 \mathrm{H}, \mathrm{q}$, $J=5.6), 3.74(4 \mathrm{H}, \mathrm{t}, J=4.4), 5.46(1 \mathrm{H}, \mathrm{t}, J=4.4), 7.56\left(2 \mathrm{H}, \mathrm{AA}^{\prime} \mathrm{XX}^{\prime}\right.$ system, $\left.J=9.2\right)$,


117.8, 125.2, 142.2, 145.6, 154.6; MS (CI) calc. for C13H19N4O4: 295.1406, found 295.1415 .

\section{Synthesis of 2-morpholinoethyl 4-aminophenylcarbamate 1}

The nitro derivative previously produced was dissolved in ethanol $(25 \mathrm{~mL})$ then $\mathrm{Pd} / \mathrm{C}(5 \%$ w/w, $250 \mathrm{mg}$ ) was added. The reaction was sealed with rubber septum and $\mathrm{H}_{2}$ from a balloon bubbled through the rapidly stirring suspension for 10 minutes. The reaction was left before stirring under an $\mathrm{H}_{2}$ atmosphere for 1 hour. The bubbling and stirring cycle was repeated twice more. The reaction was continued to completion then filtered through a pad of Celite ${ }^{\circledR}$ which was washed thoroughly with ethanol and the solvent removed to leave a brown oil which crystallised on standing, affording a yellow solid in yield of $86 \%(0.79 \mathrm{~g})$. IR (thin film) $U_{\max } / \mathrm{cm}^{-1} 3338,2958,2858,1710,1630,1601,1516,1430,1303,1227$, $1113,1067,830,516 ;{ }^{1} \mathrm{H}$ NMR (400 MHz, $\left.\mathrm{CDCl}_{3}\right) \delta 2.50$ (4H, br), $2.63(2 \mathrm{H}, \mathrm{t}, J=5.6$ ), $3.51(2 \mathrm{H}, \mathrm{br}) 3.70$ (4H, t, $J=4.4), 4.25(2 \mathrm{H}, \mathrm{t}, J=5.6), 6.60(2 \mathrm{H}, \mathrm{d}, J=8.8), 7.03(1 \mathrm{H}, \mathrm{br})$, $7.11(2 \mathrm{H}, \mathrm{d}, J=7.2) ;{ }^{13} \mathrm{C} \mathrm{NMR}\left(100 \mathrm{MHz}, \mathrm{CDCl}_{3}\right) \delta 53.7,57.5,61.4,66.8,115.5,116.7$, 121.0, 129.1, 138.6, 142.8, 154.0; MS (ESI) calc. for $\mathrm{C}_{13} \mathrm{H}_{20} \mathrm{~N}_{3} \mathrm{O}_{3}: 266.1499$, found 266.1502 .

\section{Synthesis of 1-(4-aminophenyl)-3-(2-morpholinoethyl)urea 2}

The urea $\mathbf{2}$ was produce according to the procedure used to synthesise $\mathbf{1}$ to afford $\mathbf{2}$ as a pink solid $\left(0.74\right.$ g, 83\%). m.p. $=170-171{ }^{\circ} \mathrm{C}$; IR (thin film) $U_{\max } / \mathrm{cm}^{-1} 3340,2956,2868$, $2823,1646,1602,1559,1514,1285,1225,1183,1113,684,516 ;{ }^{1} \mathrm{H}$ NMR $\left(400 \mathrm{MHz}, \delta_{6^{-}}\right.$ 
DMSO) 2.33-2.36 (6H, m), 3.15 (2H, q, $J=5.6), 3.57$ (4H, t, $J=4.8$ ), 4.68 (2H, br), 5.83 $(1 \mathrm{H}, \mathrm{t}, J=5.2) 6.45$ (2H, AA'XX' system, $J=8.6), 6.98$ (2H, AA'XX' system, $J=8.6$ ), $8.04(1 \mathrm{H}, \mathrm{s}) ;{ }^{13} \mathrm{C}$ NMR $\left(100 \mathrm{MHz}, \delta_{6}\right.$-DMSO) $\delta 36.0,53.2,58.0,66.1,114.1,120.2,129.6$, 143.3, 155.6. MS (ESI) calc. for $\mathrm{C}_{13} \mathrm{H}_{21} \mathrm{~N}_{4} \mathrm{O}_{2}$ : 265.1559, found 265.1659.

\section{Synthesis of 4-((4'-carbamic acid 2-[bismorpholine]-ethyl ester) benzyl)-phenyl- amino-carbonyl terminated poly(butadiene) diol 8}

Poly(butadiene) diol end-capped with 4,4'-methylenebis(phenylisocyanate) (8.06 g, 3.23 mmol) was dissolved in dry THF, $N$-(2-hydroxylethyl)-morpholine (0.84 g, $6.45 \mathrm{mmol})$ was added and the solution was left stirring at $50{ }^{\circ} \mathrm{C}$ for 6 hours. The solvent was removed in vacuo and 4-((4'-carbamic acid 2-[bismorpholine]ethyl ester) benzyl)-phenyl-aminocarbonyl terminated poly(butadiene) diol $\mathbf{8}$ diol was purified as a light orange viscous liquid in $88 \%$ yield $(8.06 \mathrm{~g})$ via a multiple slow precipitation in methanol. IR $\left(\mathrm{CDCl}_{3}, \mathrm{KBr}\right)$ $v_{\max } / \mathrm{cm}^{-1} ; 3324,3072,2963,2915,2843,1734,1703,1638,1598,1533,1436 ;{ }^{1} \mathrm{H}$ NMR $\left(250 \mathrm{MHz} \mathrm{CDCl}_{3}\right) \delta 1.25-2.02\left(18 \mathrm{H}_{\mathrm{n}}, \mathrm{br}\right), 2.50-2.53(8 \mathrm{H}, \mathrm{t}, J=5.0), 2.64-2.69(4 \mathrm{H}, \mathrm{t}, J=$ 5.0), 3.71-3.74 (8H, t, $J=5.0), 3.88(4 \mathrm{H}, \mathrm{s}), 4.26-4.30(4 \mathrm{H}, \mathrm{t}, J=5.0), 4.96-5.84\left(7 \mathrm{H}_{\mathrm{n}}, \mathrm{br}\right)$, 6.55-6.88 (4H, br), 7.08-7.11 (8H, AA'XX' system), 7.26-7.29 (8H, AA’XX' system); ${ }^{13} \mathrm{C}$ NMR (62.5 MHz, $\left.\mathrm{CDCl}_{3}\right) \delta 25.6,27.4,30.2,32.8,38.2,39.7,43.8,53.8,57.5,66.9,68.0$, $112.9-114.9,118.9,127.7,130.1,131.7,135.9-136.4,142.7-143.6,153.4-153.7$; GPC (THF) $\overline{\mathbf{M}}_{\mathrm{w}}$ 13079, $\overline{\mathbf{M}}_{\mathrm{n}}$ 7244, Đ 1.8.

\section{Synthesis of 4-((4'-2-[bismorpholine]-ethyl) ureidobenzyl)-phenyl-amino-carbonyl terminated poly(butadiene) 9}

This product has been produced via the direct addition approach used to synthesise polymer 8. 4-((4'-2-[Bismorpholine]-ethyl) ureidobenzyl)-phenyl-amino-carbonyl terminated poly(butadiene) diol 9 was produced as an elastomeric solid in a 97\% yield (3.18 g) from poly(butadiene) diol end-capped with 4,4'-methylenebis(phenylisocyanate) (2.88 g, 1.15 mmol) with $N$-(2-aminoethyl)-morpholin-4-(2-aminoethyl)morpholine (0.30 g, $2.31 \mathrm{mmol})$. IR $\left(\mathrm{CDCl}_{3}, \mathrm{KBr}\right) v_{\max } / \mathrm{cm}^{-1} 3337,3072,2963,2915,2844,1734,1639,1598,1544,1414$; ${ }^{1} \mathrm{H}$ NMR $\left(250 \mathrm{MHz}, \mathrm{CDCl}_{3}\right) \delta 1.25-2.02\left(18 \mathrm{H}_{\mathrm{n}}\right.$, br) $2.41-2.50(12 \mathrm{H}, \mathrm{t}, J=5.0), 3.29-3.36$ (4H, br), 3.61-3.64 (8H, t, $J=5.0), 3.88(4 \mathrm{H}, \mathrm{s}), 4.96-5.77\left(7 \mathrm{H}_{\mathrm{n}}, \mathrm{br}\right), 6.66(4 \mathrm{H}, \mathrm{br}), 7.04-$ $7.11\left(8 \mathrm{H}, \mathrm{AA}^{\prime} \mathrm{XX}\right.$ ' system), 7.26-7.29 (8H, $\mathrm{AA}^{\prime} \mathrm{XX}$ ' system); ${ }^{13} \mathrm{C} \mathrm{NMR}\left(62.5 \mathrm{MHz}, \mathrm{CDCl}_{3}\right)$ $\delta 25.0,27.4,30.2,32.7,37.4-38.4,41.0,43.5,53.3,57.8,66.8,113.8-115.0,121.2-121.5$, 
128.0, 129.4, 131.8, 136.2-136.8, 142.7-143.1, 153.7-156-2; GPC (THF) $\overline{\mathrm{M}}_{\mathrm{w}} 10229, \overline{\mathrm{M}}_{\mathrm{n}}$ 6010, Đ 1.7 .

\section{Synthesis of bis(4-(4-(3-(4-(3-(2-morpholinoethyl)ureido) phenyl)ureido)} benzyl)phenylcarbamate) terminated poly(butadiene) 10

This product has been produced via the direct addition approach used to synthesise polymer 8. 4-((4'-2-[Bismorpholine]-ethyl)ureidobenzyl)-phenyl-amino-carbonyl terminated poly(butadiene) diol 10 was produced as a pink elastomeric solid in a 95\% yield (7.20g) from poly(butadiene) diol end-capped with 4,4'-methylenebis(phenylisocyanate) $(6.25 \mathrm{~g}$, $2.5 \mathrm{mmol})$ with $(1.32 \mathrm{~g}, 5.0 \mathrm{mmol})$ 2-morpholinoethyl 4-aminophenylcarbamate $\mathbf{1}$. IR $\left(\mathrm{CDCl}_{3}, \mathrm{KBr}\right) v_{\max } / \mathrm{cm}^{-1} 3309,3072,2969,2915,2843,1728,1711,1693,1595,1519$, 1412; ${ }^{1} \mathrm{H}$ NMR $\left(250 \mathrm{MHz}, \mathrm{CDCl}_{3}\right) \delta$ 1.25-2.02 (18H, br) $2.51(8 \mathrm{H}, \mathrm{br}), 2.65$ (4H, br), 3.69 $(8 \mathrm{H}, \mathrm{br}), 3.80-3.87(4 \mathrm{H}, \mathrm{m}), 4.26-4.34(4 \mathrm{H}, \mathrm{br}), 4.96-5.79\left(7 \mathrm{H}_{\mathrm{n}}, \mathrm{br}\right), 6.55(4 \mathrm{H}, \mathrm{br}), 6.85-$ 6.87 (4H, br), 7.04-7.47 (24H, br); ${ }^{13} \mathrm{C} \mathrm{NMR}\left(62.5 \mathrm{MHz}, \mathrm{CDCl}_{3}\right)$ \& 25.0, 27.4, 28.6, 32.0, 38.2 , 41.7, 43.6, 53.8, 57.5, 61.7, 66.8, 113.8-115.1, 119.1-121.5, 128.3, 130.2, 131.8, 135.8-136.2, 142.7-143.4, 153.9; GPC (THF) $\overline{\mathrm{M}}_{\mathrm{w}}$ 12538, $\overline{\mathrm{M}}_{\mathrm{n}} 7249$, 1.7 .

\section{Synthesis of 4-((4'-2-[bismorpholine]-ethyl) ureidobenzyl)-phenyl-amino-carbonyl terminated poly(butadiene) 11}

This product has been produced via the direct addition approach used to synthesise polymer 8. The 4-((4'-carbamic acid 2-[bisbutyl-amino]-ethyl ester) benzyl)-phenyl-aminocarbonyl terminated poly(butadiene) diol 11 was produced as an elastomeric solid in $84 \%$ yield (1.65 g) from poly(butadiene) diol-end capped with 4,4'methylenebis(phenylisocyanate) (1.63 g, $0.625 \mathrm{mmol})$ with 1-(4-aminophenyl)-3-(2morpholinoethyl)urea $(0.33 \mathrm{~g}, 1.25 \mathrm{mmol})$ 2. IR $\left(\mathrm{CDCl}_{3}, \mathrm{KBr}\right) v_{\max } / \mathrm{cm}^{-1} 3316,3072,2969$, 2915, 2845, 1731, 1711, 1635, 1514, 1413; ${ }^{1} \mathrm{H}$ NMR (250 MHz, $\left.\mathrm{CDCl}_{3}\right) \delta 1.25-2.03\left(18 \mathrm{H}_{\mathrm{n}}\right.$, br), 2.25-2.48 (12H, br), 3.28-3.34 (4H, q, $J=5.0), 3.60-3.64(8 \mathrm{H}, \mathrm{t}, J=5.0), 3.88$ (4H, s), 4.96-5.80 (7H $\mathrm{n}$, br), 6.44-6.59 (10H, br), 6.63-7.29 (24H, m); ${ }^{13} \mathrm{C} \mathrm{NMR}\left(62.5 \mathrm{MHz}, \mathrm{CDCl}_{3}\right)$ $\delta$ 25.0, 27.4, 30.2-30.3, 32.7, 36.7, 38.2, 41.1, 53.2, 57.5, 67.0, 113.8-115.0, 115.7, 117.0, 128.2, 130.6, 136.1, 142.7-144.3, 157.3; GPC (THF) $\overline{\mathrm{M}}_{\mathrm{w}}$ 12477, $\overline{\mathrm{M}}_{\mathrm{n}} 6609$, Đ 1.88.

\section{Synthesis of 2-morpholinoethyl phenylcarbamate 12}

Phenyl isocyanate $(4.2 \mathrm{mmol}, 0.50 \mathrm{~g})$ was added to 2-morpholinoethan-1-ol (4.2 mmol, $0.55 \mathrm{~g})$ in dry THF $(10 \mathrm{~mL})$ and the mixture was stirred for 16 hours at room temperature. 
The solvent was then removed in vacuo to afford compound $\mathbf{1 2}$ as a white powder, $0.96 \mathrm{~g}$, 91\%. Mp $104{ }^{\circ} \mathrm{C}$; IR (ATR) $v_{\max } / \mathrm{cm}^{-1} 1222,1313,1445,1500,1567,1720,2816,2866$, 2950, 3140, 3257; ${ }^{1} \mathrm{H}$ NMR (400 MHz; $\left.\mathrm{CD}_{3} \mathrm{Cl}_{3}\right) \delta 2.53(4 \mathrm{H}, \mathrm{t}, J=4.4), 2.67(2 \mathrm{H}, \mathrm{t}, J=$ 5.6), $3.73(4 \mathrm{H}, \mathrm{t}, J=4.8), 4.30(2 \mathrm{H}, \mathrm{t}, J=5.6), 6.79(1 \mathrm{H}, \mathrm{br}), 7.06(1 \mathrm{H}, \mathrm{t}, J=7.6), 7.28$ $7.38(4 \mathrm{H}, \mathrm{m}) ;{ }^{13} \mathrm{C} \mathrm{NMR}\left(100 \mathrm{MHz} ; \mathrm{CDCl}_{3}\right) \delta 53.8,57.5,61.8,66.8,118.6,123.51,129.1$, $137.8,153.4$.

\section{Synthesis of 1-(2-morpholinoethyl)-3-phenylurea 13}

Phenyl isocyanate (3.8 mmol, $0.46 \mathrm{~g}$ ) was added to 2-morpholinoethan-1-amine (3.8 mmol, $0.50 \mathrm{~g})$ in dry THF $(10 \mathrm{~mL})$ and the mixture was stirred for 16 hours at room temperature. The solvent was then removed in vacuo to afford compound $\mathbf{1 3}$ as a white powder, $0.89 \mathrm{~g}$, 94\%. Mp $140{ }^{\circ} \mathrm{C}$; IR (ATR) $v_{\max } / \mathrm{cm}^{-1} 1243,1309,1442,1550,1594,1653,2811,2857$, 2940, 2969, 3310; ${ }^{1} \mathrm{H}$ NMR (400 MHz; $\mathrm{CD}_{3} \mathrm{Cl}_{3}$ ) $\delta 2.34$ (4H, br), 2.38 (2H, t, $J=6.0$ ), 3.28 (2H, q, $J=5.6), 3.59$ (4H, br), $6.15(1 \mathrm{H}, \mathrm{s}), 6.96(1 \mathrm{H}, \mathrm{t}, J=7.6), 7.20(2 \mathrm{H}, \mathrm{t}, J=7.6), 7.31$ $(2 \mathrm{H}, \mathrm{d}, J=7.6) ;{ }^{13} \mathrm{C} \mathrm{NMR}\left(100 \mathrm{MHz} ; \mathrm{CDCl}_{3}\right) \delta 36.8,53.4,57.9,66.8,119.8,122.7,128.9$, 139.3, 156.8 .

\section{Acknowledgements}

The authors would like to thank EPSRC (EP/J010715/1 and EP/J011436/1) for postdoctoral fellowships for AF and IG; EP/G026203/1 and EP/D07434711 for BWG), and Henkel UK Ltd for PhD studentships for DHM and KM. Spectroscopic and thermal data were acquired in the Chemical Analysis Facility at the University of Reading. AFM and TEM images were obtained using the Electron Microscopy Laboratory (EMLab) at the University of Reading and the microscopy facilities at the University of Surrey.

\section{References}

(1) Hinrichsen G. Acta Polym 1994;45: 398.

(2) Houton KA, Wilson AJ. Polym Int 2015;64: 165-173.

(3) Shelke NB, Nagarale RK, Kumbar SG. In Natural and Synthetic Biomedical Polymers, Elsevier, Oxford, 2014, 123-144.

(4) Hutin M, Burakowska-Meise E, Appel WPJ, Dankers PYW, Meijer, EW. Macromolecules 2013;46: 8528-8537.

(5) Yilgör I, Yilgör E. Polym Rev 2007;47: 487-510. 
(6) Stadler R, Freitas LD. Colloid Polym Sci 1986;264: 773-778.

(7) Houton KA, Burslem GM, Wilson AJ. Chem Sci 2015;6: 2382-2388.

(8) Feula A, Pethybridge A, Giannakopoulos I, Tang X, Chippindale AM, Siviour CR, Buckley CP, Hamley IW, Hayes W. Macromolecules 2015;48: 6132-6141.

(9) Felder T, de Greef TFA, Nieuwenhuizen MML,Sijbesma RP. Chem Commun 2014;50: 2455-2457.

(10) Li J., Viveros JA, Wrue, MH, Anthamatten M. Adv Mater 2007;19: 2851-2855.

(11) Feldman KE, Kade MJ, Meijer EW, Hawker CJ, Kramer EJ. Macromolecules 2009;42:9072-9081.

(12) Bang J, Jeong U, Ryu DY, Russell TP, Hawker CJ. Adv Mater 2009;21:4769_ 4792.

(13) Ducrot A, Verwilst P, Scarpantonio L, Goudet S, Kauffmann B, Denisov S, Jonusauskas G, McClenaghan ND. Supramol Chem 2012;24:462-472.

(14) Murakami H, Baba R, Fukushima M, Nonaka N. Polymer 2015;56:368-374.

(15) Yilgör I, Yilgör E, Wilkes GL. Polymer 2015;58:A1-A36.

(16) Das S, Cox DF, Wilkes GL, Klinedinst DB, Yilgör I, Yilgör E, Beyer FL. J Macromol Sci Part B 2007;46:853-875.

(17) Liu S, Tian M, Yan B, Yao Y, Zhang L, Nishi T, Ning N. Polymer 2015;56:375384.

(18) Laity PR, Taylor JE, Wong SS, Khunkamchoo P, Norris K, Cable M, Andrews GT, Johnson AF, Cameron RE. Polymer 2004;45:5215-5232.

(19) Sami S, Yildirim E, Yurtsever M, Yurtsever E, Yilgör E, Yilgör I, Wilkes GL. Polymer 2014;55:4563-4576.

(20) Stuparu MC, Khan A, Hawker CJ. Polym Chem 2012;3:3033-3044.

(21) Hosono N, Pitet LM, Palmans ARA, Meijer EW. Polym Chem 2014; 5:1463-1470.

(22) Gooch A, Nedolisa C, Houton KA, Lindsay CI, Saiani A, Wilson AJ. Macromolecules 2012;45:4723-4729.

(23) Wrue MH, McUmber AC, Anthamatten M. Macromolecules 2009;42 :9255-9262.

(24) De Greef TFA, Smulders MMJ, Wolffs M, Schenning APHJ, Sijbesma RP, Meijer EW. Chem Rev 2009;109:5687-5754.

(25) Klinedinst DB, Yilgör I, Yilgör E, Zhang, M, Wilkes GL. Polymer 2012;53:53585366.

(26) Yilgör E, Yilgör İ, Yurtsever E. Polymer 2002;43:6551-6559.

(27) Buckwalter, DJ, Inglefield DL, Enokida JS, Hudson AG, Moore RB, Long TE. Macromol Chem Phys 2013;214:2073-2082.

(28) Pitet LM, van Loon AHM, Kramer EJ, Hawker CJ, Meijer EW. ACS Macro Lett 2013;2:1006-1010.

(29) Colombani O, Barioz C, Bouteiller L, Chanéac C, Fompérie L, Lortie F, Montès H. Macromolecules 2005;38:1752-1759. 
(30) Botterhuis NE, van Beek DJM, van Gemert GML, Bosman AW, Sijbesma RP. J Polym Sci Part A Polym Chem 2008;46:3877-3885.

(31) Botterhuis NE, Karthikeyan S, Spiering AJH, Sijbesma RP. Macromolecules 2010;43:745-751.

(32) Dankers PYW, Zhang Z, Wisse E, Grijpma DW, Sijbesma RP, Feijen J, Meijer EW. Macromolecules 2006;39:8763-8771.

(33) Van Beek, DJM, Spiering AJH, Peters GWM, te Nijenhuis K, Sijbesma RP. Macromolecules 2007;40:8464-8475.

(34) Flory PJ. J Chem Phys 1949;17: 303-310.

(35) Yan TZ, Schroter K, Herbst F, Binder WH, Thurn-Albrecht T. Macromolecules 2014;47;2122-2130.

(36) Callies X, Fonteneau C, Vechambre C, Pensec S, Chenal JM, Chazeau L, Bouteiller L, Ducouret G, Creton C. Polymer 2015;69;233-240.

(37) Callies X, Vechambre C, Fonteneau C, Pensec S, Chenal JM, Chazeau L, Bouteiller L, Ducouret G, Creton C. Macromolecules 2015;48;7320-7326.

(38) Versteegen RM, Sijbesma RP, Meijer EW. Macromolecules 2005;38:3176-3184.

(39) Fox, JD, Rowan SJ. Macromolecules 2009;42:6823-6835.

(40) Coulibaly S, Roulin A, Balog S, Biyani MV, Foster EJ, Rowan SJ, Fiore GL,Weder C. Macromolecules 2014;47:152-160.

(41) Fiore GL, Rowan SJ, Weder C. Chem Soc Rev 2013;42:7278-7288.

(42) Woodward PJ, Hermida Merino D, Greenland BW, Hamley IW, Light Z, Slark AT, Hayes W. Macromolecules 2010;43:2512-2517.

(43) Woodward P, Merino DH, Hamley IW, Slark AT,Hayes W. Aust J Chem 2009;62:790-793.

(44) Woodward P, Clarke A, Greenland, BW, Hermida Merino D, Yates L, Slark AT, Miravet JF, Hayes W. Soft Matter 2009;5:2000-2010.

(45) Merino DH, Slark AT, Colquhoun HM, Hayes W, Hamley IW. Polym Chem 2010;1:1263-1271.

(46) Burattini S, Greenland BW, Merino DH, Weng W, Seppala J, Colquhoun HM, Hayes W, Mackay ME, Hamley IW, Rowan SJ. J Am Chem Soc 2010;132:1205112058.

(47) Gooch A, Murphy NS, Thomson NH, Wilson AJ. Macromolecules 2013;46:96349641.

(48) Rozas I, Alkorta I, Elguero J. J Phys Chem A 1998;102: 9925-9932.

(49) Versteegen RM, Kleppinger R, Sijbesma RP, Meijer EW. Macromolecules 2006;39:772-783.

(50) Pape ACH, Bastings MMC, Kieltyka RE, Wyss, HM, Voets IK, Meijer EW, Dankers PYW. Int J Mol Sci 2014;15:1096-1111.

(51) Sheth JP, Aneja A, Wilkes GL. Polymer 2004;45:5979-5984. 
(52) Öjelund K, Loontjens T, Steeman P, Palmans A, Maurer F. Macromol Chem Phys 2003;204: 52-60.

(53) Portale G, Cavallo D, Alfonso GC, Hermida-Merino D, van Drongelen M, Balzano L, Peters GWM, Goossens JGP, Bras W. J Appl Cryst 2013;46:1681-1689.

(54) AgilentTechnologies 2012. Agilent Technologies UK Ltd., Oxford, UK, Xcalibur/SuperNova CCD system, CrysAlisPro Software system, Version 1.171.36.21.

(55) Altomare A, Cascarano G, Giacovazzo C, Guagliardi A, Burla, MC, Polidori G, Camalli M. J Appl Cryst 1994;27:435.

(56) Betteridge PW, Carruthers JR, Cooper RI, Prout CK, Watkin DJ. J Appl Cryst 2003;36:1487. 